\title{
Personal Qualities of Effective Sport Psychologists: A Sports Physician Perspective
}

Authors' contribution:

A) conception and design of the study

B) acquisition of data

C) analysis and interpretation of data

D) manuscript preparation

E) obtaining funding

\author{
Charlotte Chandler ${ }^{\text {A-D }}$, Martin Eubank ${ }^{\text {ACD }}$, Mark Nesti ${ }^{\text {ACD }}$, \\ Tim Cable ${ }^{\mathrm{E}}$
}

Liverpool John Moores University, England

\begin{abstract}
Previous literature within applied sport psychology offers little detailed discussion regarding the personal qualities of sport psychology practitioners and the impact of these qualities on practice. This paper presents an exploration of the views of sport physicians regarding the personal characteristics and qualities of applied sport psychologists deemed necessary for effective practice. Five UK-based physicians and one Head of Medical Services, working in a range of elite and professional sports, were interviewed about their experience and perceptions of working with sport psychologists. The interview transcripts were content analysed and trustworthiness criteria applied. Four key themes emerged from the data, labelled 'Personal qualities', 'Relationship Building', 'Professionalism in Practice', and 'Similarities between Psychologist and Physician'. The findings within each theme offered interesting insights into the impact of personal qualities on effective sport psychology practice. This study extends the existing literature on sport psychologists' characteristics and effectiveness and offers new insights into their personal qualities and how these interact with the practice environment. The findings supported the growing emphasis within the field on the importance of the person behind the practitioner. Suggestions are offered with reference to the need to consider how literature from counselling psychology and medical training could assist the development of practice and education and training in sport psychology.

consultant effectiveness, applied sport psychology practice
\end{abstract}

\section{Introduction}

In recent years, the field of applied sport psychology has broadened to encompass not only the use of problem-solving approaches concerned with mental skills training, but also more humanistic, person-centred approaches that utilise skills grounded in counselling (Hack, 2005). Research regarding the relative merits of these diverse approaches and how they influence the effectiveness of applied practice has begun to permeate 
the literature base (e.g. Gilbourne \& Richardson, 2006; Lindsay, Breckon, Thomas, \& Maynard, 2007). In addition, literature is beginning to appear which argues that the personal qualities of the sport psychologist are implicated in their ability to be effective in their work (Nesti, 2004). Within the counselling psychology profession, the personal qualities of the practitioner, such as empathy and congruence, are considered to play a significant role in developing an effective therapeutic relationship with a client, which in turn will dictate the quality of the therapeutic outcome (Corey, 2009). The same could therefore be said for a sport psychologist seeking to operate in a similar manner (Hack, 2005), especially if:

"the sport psychologist is the primary consulting tool and the practitioner-athlete relationship is the main intervention" (Tod \& Andersen, 2005, p. 309).

Strupp contends that:

"the therapist's theoretical orientation...is over-determined and deeply rooted in one's biography. To understand the mainsprings of a therapist's theoretical orientation, one has to understand the therapist as a person" (1978, p. 314).

Many of the personal qualities described in the counselling literature can be summarised as representing empathy, non-possessive warmth and genuineness, which in turn can be likened to the conditions proposed by Carl Rogers in 1957 as necessary and sufficient for behaviour change. These represent descriptions of the therapist's attitudes and personal qualities rather than just effective techniques. (Truax \& Carkhuff, 1976). Thus, emphasis is placed on the therapist's personal qualities, rather than their practical skills.

The importance of a practitioner's personal qualities has been acknowledged in the sport psychology literature, but to a much lesser degree. Orlick and Partington (1987) noted that sport psychologists who became "excellent" consultants began with certain personal qualities, experiences and good interpersonal skills, and then went on to learn about their field through academic degrees and supervised experience in the field. Corlett in discussing the traditions of Sophist and Socratic philosophies, states that:

"the most difficult counselling situations often illuminate the difference between curing and caring. The demand is seldom on one's competence in the psychology of sport, but often on one's competence in the humanity of sport" (1996, p. 91).

The sport psychologist as a person is therefore implicated as an important influence within an approach to practice driven by Socratic values, where an athlete's problems are considered to result from a deficiency in knowledge of self. The rigorous self-examination necessary for the athlete to create an honest appraisal of their problem requires particular skills and personal qualities within the sport psychologist to enable them to be effective in facilitating and empowering change.

Specifically, Nesti $(2004,2010)$ makes reference to personal qualities such as empathy and trustworthiness in relation to existential counselling in sport psychology, along with presence, authenticity and spontaneity. Presence refers to the practitioner remaining fully engaged with their client (Nesti, 2004) and relates to the Rogerian condition whereby the two parties are aware of being in personal or psychological contact with one another (Rogers, 1957). Authenticity has been described as owning one's personal experiences and acting in accordance with the true self, thus "expressing oneself in ways that are consistent with inner thoughts and feelings" (Harter, 2002, p. 382). Spontaneity is a key component of authenticity, as speaking in a spontaneous way allows one to reveal their authentic selves and approach a situation without the distraction of self-consciousness (Nesti, 2010). The similarities between counselling psychology practice and that of sport psychologists are clear based upon Nesti's descriptions of the latter's personal qualities, but it remains necessary to address the limited previous research on this topic. Therefore, the purpose of this research was to examine the personal qualities deemed necessary for effective sport psychology practice.

Such previous literature has focussed mainly on perspectives from coach and athlete populations, and has highlighted and discussed what could be considered effective sport psychologists' skillsrather than personal qualities. For example Anderson, Miles, Robinson and Mahoney (2004) highlighted skills such as 
good communication, providing feedback, and getting to know the athletes. The perspective of other sport professionals with whom sport psychologists are likely to develop a close working alliance, such as the sports physician, would offer an insightful and unique view of their personal qualities in practice. Significantly, the importance of character and personal qualities as indicators of success within effective physicians has received research attention. Character, integrity, personality, and attitude have all been cited as impacting the effectiveness of physicians (McGaghie, 1990; Glick, 2000), and are consequently a feature of their education and training. The medical professional therefore offers an interesting parallel, as akin to that of a sport psychologist their practice is underpinned by a professional training and qualification framework housed within an established governing body, which results in the potential for significant impact on athlete well-being. Given this and the often difficult and challenging sporting environments within which they both work (Glick, 2000; Nesti, 2010), sport physicians were deemed to be a population who could offer genuine insights pertaining to the effective practice of sport psychology.

\section{Method}

\section{Participants}

A sample of five sport physicians (four males and one female) and one Head of Medical Services (male), who had worked or were currently working with sport psychologists, gave their informed consent to be interviewed. The participants worked within a range of elite sports (e.g. Premier League football, rugby, gymnastics, boxing, and several other Olympic sports). The sport physicians had all worked as general practitioners prior to their involvement in sport, with their experience of working with sport psychologists ranging between eighteen months and ten years. The Head of Medical Services was a physiotherapist by training but had over ten years of experience in their current role. Participants' experiences of sport psychologists' work included collaboration as part of a multidisciplinary support team, where the sport psychologists' roles included educational group sessions, as well as one-to-one counselling with athletes and working closely with coaches and other colleagues. This degree of exposure to and interaction with sports psychologists gave these physicians unique insights relating to the specific personal qualities that facilitated effective sport psychology practice.

\section{Instrument}

Data collection took the form of a semi-structured one-to-one interview with each participant. The questions were open-ended to allow the participants to fully express their thoughts and opinions, and ensure the responses were truly representative of their experiences in practice. Probing questions were utilised where necessary to further explore the subjects' accounts, encouraging them to elaborate on information pertinent to the research question (Berg, 2009). The interview structure was developed after reviewing the methodologies used in the previous sport psychologist effectiveness literature (e.g., Orlick\&Partington, 1987; Anderson et al., 2004), and its content was adapted to address the specific research question and made relevant to the participant group.

\section{Procedure}

Following ethical approval, five sport physicians and a Head of Medical Services were approached through purposive sampling of the contacts of the authors (Patton, 2002). The six participants were selected because of their close working relationships with sport psychologists, therefore providing them with a high level of collaborative insight to inform powerful and detailed discussions of their experiences. The six participants were interviewed in person at a location suitable to them, either at work or at home. Each physician was provided with the interview guide and a participant information sheet in advance, which detailed the interview questions and procedure and informed them that the data would be kept confidential and of their right to withdraw. The interviews typically lasted $60-90$ minutes. 


\section{Data analysis}

Each interview was recorded and transcribed verbatim, reviewed for grammatical accuracy, and reread for familiarity by the first author. Transcripts yielded 144 pages of 1.5 spaced interview data. Data was then analysed through the use of content analysis, defined by Patton as:

"any qualitative data reduction and sense-making effort that takes a volume of qualitative material and attempts to identify core consistencies and meanings" (2002, p. 453).

This qualitative data analysis protocol has been used previously within similar interview based research studies (Anderson et al., 2004). Each salient quotation was tagged to identify the interviewee from which it originated, allowing the researchers to identify the contributors for ease of reference between and within interviews.

\section{Researcher trustworthiness}

Research credibility principles were used to ensure a true representation of the data (Shenton, 2004). Firstly, a description of the lead author's research background was provided to the participants, given that the lead author was the primary instrument in data collection and analysis (Patton, 2002). Providing such information also aids the reader in their judgement of the trustworthiness of the research (Anderson et al., 2004). Prior to this study, the lead author had completed and contributed to several qualitative research projects and was therefore experienced in conducting research interviews. This previous research also provided the first author with a thorough knowledge of the literature base pertaining to the current study. Although participants were recruited to the study through purposive sampling, effort was made to ensure they represented as diverse a range of sports and experience as possible, therefore ensuring data was collected from multiple and varied sources. Member checking was also employed, whereby each transcript was sent via email to their respective participant for confirmation that the content could be analysed and discussed, and with the option of editing or deleting content. The accuracy, fairness, completeness and validity of all data transcripts were therefore confirmed (Patton, 2002). Analyst triangulation was achieved through frequent meetings between the authors at each stage of data analysis to discuss the findings, thereby offering a wider perspective from which to develop interpretations of the data and allowing their interpretations to be debated and the common themes to be confirmed (Shenton, 2004).

\section{Results}

Based on analysis of the transcripts, data representation was built around four key emergent topics. The first examined the physicians' perceptions of the personal qualities of sport psychologists deemed beneficial for effective sport psychology practice. Secondly, the manner in which sport psychologists utilised these qualities to build relationships, and thirdly their use in displaying professionalism was explored. The final topic examined sport physicians' comparisons of the emerging personal qualities to their own experiences in medical practice.

\section{Personal qualities}

The physicians discussed a number of personal qualities they had experienced in effective sport psychologists or believed they should possess. One physician described the qualities and beliefs that they valued in the sport psychologist they had worked with:

"Character traits in terms of being open and honest and decent and fair...the idea that somebody can improve or people are prone to error and that's normal, yeh I think [they are] traits of a human being that I respect" 
This quote highlights the physician's assessment of the sport psychologist as a person as well as a practitioner, and the values that they hold. The physicians also discussed the personal qualities of empathy and trustworthiness as essential for effective practice as a sport psychologist:

"I think empathy and honesty and trustworthiness...you have to strive to have an understanding of what's driving your patient and you have to care, and if you do both of those you'll be honest and trustworthy...Being a good listener and being open and trustworthy are probably the most important things...but without the right environment and the right experience and then the right openness, trustworthiness, you need all of that before you can even start to be a psychologist and modify people".

Empathy in particular was deemed an essential quality that enabled the sport psychologists to communicate effectively with their athletes:

\begin{abstract}
"If you're dealing with other human beings, to get the best out of them you've got to able to communicate well, so you've got to have empathy with them... You have to have a good understanding of what an athlete is going through...do I have to have been an elite athlete, no, do I have to understand what kind of sacrifices they make, yes...in other ways have I made similar-ish sacrifices to my life, yes...use whatever your personal experiences are and I think it's important that you're able then to sometimes relate that to the athlete you're talking to".
\end{abstract}

These extracts suggest that an ability to empathise and communicate this empathy to an athlete is a quality necessary for practice within a profession that is primarily concerned with people. Furthermore, an athlete in an elite sporting environment will be focussed on achieving performance excellence, and thus the sport psychologist must possess the ability to empathise with the athlete's experience and aid them in realising their potential. Trust was also considered a related key quality that sport psychologists must value and be able to establish between themselves and the athletes they work with. This was discussed both in terms of trust in the sport psychologist as a person, and also in their professional skills:

"[You need] a knowledge base that makes it obvious to the person you're dealing with that you've dealt with this sort of thing before, to have trust in you, not just you as a person, but trust in your clinical skills"

Results seem to indicate that practitioners operating within a "caring", people-orientated profession, such as medicine or psychology, must endeavour to understand their patient and be naturally driven to care for them. It appears necessary for an individual to possess such a quality in order to ensure that they are also empathic and trustworthy.

\title{
Relationship Building
}

The physicians emphasised certain personal qualities that were considered to significantly impact upon the ability of a sport psychologist to build effective working relationships. One physician emphasised how important they perceived personal qualities to be with regards to it being these that enable them to communicate and connect with others and stated:

"it's about personality...none of this is about how clever you are, it's always a mistake to think that if you're super bright that you're good at talking to people".

More specifically, personal qualities described by physicians also included being approachable, agreeable, and possessing the general ability to get on with people. It appears to be a quality of a sport psychologist that enables them to create a connection and thus build 'real' relationships with athletes and colleagues:

"it's just a natural ability to connect with people...not everybody can do that, some people can some people can't, but the couple of psychologists who haven't been quite so successful have struggled with that". 
Trust was discussed by all physicians as of great importance when building connections and therefore relationships. Doing so allows for effective sport psychology practice, which is considered essential when working as part of a multidisciplinary team, as described by one physician:

"if you haven't got a relationship with someone you don't trust them... a team works well if everyone respects each other and trusts each other and gets on with each other...forming a relationship and maintaining it is absolutely crucial".

Such a connection can be created by the sport psychologist by making the athletes feel at ease and gaining their trust and respect, which in part is down to the psychologist themselves being a 'normal' person. Physicians described this "normal" person as being someone who their clients could connect with in a social or friendship capacity, as well as a professional one:

"they trusted him...partly because he was a normal guy... who had a good sense of humour and went out and enjoyed himself with the players and the manager".

Therefore, the physicians considered the sport psychologist who is able to establish a connection will have a good sense of humour, and be friendly and open towards others. Akin to the "good human traits" earlier described, such qualities were valued in developing respect and trust with athletes. What is clear is that the physicians perceived a need for such personal qualities to compliment the sport psychologist's academic knowledge and formal education, thus creating the foundation for effectiveness, supported by the following quote:

"if you're of a certain age and you're a university professor and you're open, you have both the...educational kudos and gravitas and the open, friendly personality, it's quite a nice blend of things to have".

\section{Professionalism in Practice}

Professionalism in practice represents physicians' views of sport psychologists relative to their competence, ethical practice, ability to work within a multidisciplinary team, and humility. One physician discussed their experience of a sport psychologist who they perceived to be working outside the boundaries of what they were qualified to do, and offered their opinion as to why this may have occurred:

"[I worry that they are] creating a dependency on the player, so only that player can speak to them about those things...you can't get rid of me because I'm so important to the team that they can only talk to me...I think fear is one of the underlying reasons why they delve down those aspects...I think that there are some insecurities, either in their self or in their role or both that make them go down these routes".

A sense of security appeared to refer to the self-confidence the sport psychologist had in their possession of the skills and personal qualities required to be effective in their role. One physician described this as a characteristic or quality of the sport psychologist and commented:

"I'm not sure that everyone can [be a sport psychologist] ...just with training etcetera...I think that's particular of anyone working with athletes...you have to have a certain security in yourself"'.

Therefore physicians appeared to perceive that a person insecure by nature, or lacking selfconfidence, would not be suited to the world of sport psychology support work, especially considering the nature of the sporting environment, which the physician described as "malevolent" and "high-pressured". The physician contended that perhaps the sport psychologist in question, as part of a multi-disciplinary support team, may have felt a need to prove themselves and cement their position within the team. Thus, the sport psychologist was perceived to be addressing athlete issues outside of their boundaries of competence, and not sharing the nature of their work with the team. 


\section{Similarities between psychologist and physician}

The physicians in the study offered several interesting comparisons between sport psychologists' work and their own. One physician discussed the influence that the sport psychologist's or physician's personality and presence can have on the outcome of a consultation:

"The idea that the intervention is the person, or their ability to work...it's the same as a $G P$...the idea that there is a placebo effect from just the doctor, the doctor is a drug himself...the idea that you come into that environment and your ability to heal is very much to do with your own personality and your own ability to deal with people... I would've thought the same sorts of things would apply to psychologists"

Such qualities were considered to impact significantly upon the 'healing process'. The same physician spoke of the learning curve that exists for both physicians and sport psychologists in terms of developing the 'knack' to swiftly create rapport with patients during consultations:

"There's a lot of personal development that could only really occur by giving consultations, in the same way as a GP, I can see somebody now... and have a rapport with my patient in under ten minutes, I couldn't have done that in half an hour...ten years ago...that knack only comes with time and with practice"

A final comparison made between sport psychologists and physicians focussed on the practitioner being suited to that particular role. The person behind the practitioner is again brought to the fore, in particular their underlying drive to care for their patients and their ability to communicate:

"People who want to build machines and do Lego and...don't want to talk to people they become surgeons and orthopaedic surgeons, people who are more interested in the person underneath the illness will probably become a GP...to be a GP or a psychologist you've got to talk to people, and communicate with people, to be a surgeon you have to do a bit of that but, a bit less so"

"I might say...go and see this bloke, they're not the most gifted communicator but they're a bloody good surgeon for instance, that doesn't matter...because you're sending them to have some surgery, but as a communicator and psychologist that's essential"

The physicians here are emphasising that due to the caring nature of general practice and psychology as professions, greater emphasis is placed on the personal qualities of the practitioner, in contrast to a skillfocussed profession such as that of a surgeon.

\section{Discussion}

The purpose of this research was to examine the personal qualities of sport psychologists and better understand how they contribute to their effective practice. Previous research within the sport psychology domain has afforded some attention to the characteristics of effective sport psychologists (Anderson et al., 2004), yet has generally failed to focus upon the more personal qualities of effective sport psychologists and their influence on practice. The current study extends previous research by establishing personal qualities of practitioners and how they can manifest in their practice. One physician referred to the 'good human traits' of the sport psychologist they had worked with, which emphasises the person behind the practitioner, and resonates with that of Jones (2007), who discussed the need to develop sport psychology practitioners who do the right thing, at the right time and for the right reasons, and who understand the virtues of trust, integrity and courage. In addition, physicians perceived empathy to be a prerequisite to effective sport psychology practice and as aiding practitioners in communicating and building a relationship with an athlete. Empathy is widely considered within counselling psychology to be a quality that must be portrayed by a therapist if they are to be effective in their work. Rogers (1957) cited empathy as one of the conditions necessary for therapeutic change; understanding the client's world and communicating this understanding to the client is essential. 
The trustworthiness of the sport psychologist was another quality cited frequently by the physicians and has been further emphasised within the literature (Dorfman, 1990; Cropley, Miles, Hanton \& Niven, 2007; Fifer, Henschen, Gould \& Ravizza, 2008). In particular, trust was valued as a characteristic of the sport psychologist as a person, perceived as a necessary prerequisite to forming a connection with individuals, and considered particularly important in their ability to build and maintain relationships with athletes and colleagues. Nesti (2010) states that sport psychologists and athletes "will be unable to do useful and meaningful work together without developing trust and a strong working relationship" (p. 40), and it has long been the contention within counselling psychology that the success of therapy is dependent on the quality of the relationship between the therapist and client, the maintenance of which will be impacted by the therapist's personal qualities (Corey, 2009).

The physicians frequently mentioned being agreeable, approachable, and friendly, and having the ability to 'get on' with the people around them as qualities of a sport psychologist that enabled them to establish relationships with athletes and colleagues. Physicians also suggested that the personal qualities of the sport psychologist are not sufficient in isolation to have significant impact on their effectiveness. Sport psychologists require a 'blend of characteristics', which includes possession of some/all of the personal qualities identified, combined with a strong theoretical knowledge base and good professional skills, and the ability to 'read' the environment. Taylor (2008) suggests a sport psychologist can establish credibility through academic accomplishment, previous consulting experience, and expression of one's personality. Of significance is that Taylor equates the sport psychologist's establishment of credibility to building trust with the athlete, which is known to be a significant feature of an effective working relationship (Nesti, 2010), and which was described by the physicians in this study.

Physicians in the current study also discussed how a sport psychologist's personal qualities can interact with their professional role. One physician described a sport psychologist who they perceived to be operating outside of their professional boundaries, and posited that this may be due to insecurity, or a lack of self-confidence, that extended to their perceived ability within their role and an apparent reluctance to work with other well-qualified professionals, which appeared to engage the sport psychologist in issues outside of their competence. This notion of insecurity relates to the quality of authenticity, whereby one is accepting and trusting of themselves and their choices despite the anxiety that may accompany (Nesti, 2004; Friesen \& Orlick, 2010). Fifer et al. (2008) state that a large part of a sport psychologist's effectiveness comes from their uniqueness and comfort in themselves and their approach. Therefore, as witnessed by the physician, an insecure and potentially inauthentic sport psychologist may be predisposed to practicing ineffectively, particularly in relation competence and professional boundaries.

A security of self was also considered necessary for a sport psychologist to recognise the small part they play in an athlete's success. The physicians' believed that a unique quality of a sport psychologist is their subtlety, or ability to take a withdrawn approach, which allows the sport psychologist to observe things from more of a creative, lateral perspective and subsequently make novel suggestions. A sport psychologist must be helpful without becoming a central figure, and the athlete's needs must take precedence (Balague, 1999). They must also prioritise the athlete's welfare and well-being and 'stay in the background' when working with clients (Stambulova \& Johnson, 2010). The physicians also discussed how a sport psychologist, who considers themselves of too great an importance, will be unable to read the environment and relate to those within it. Dorfman (1990) supports this view; for a sport psychologist to demonstrate professionalism they "must have limited ego needs and be self-effacing rather than self-serving" (p. 344). It could be argued that individuals such as those described by the physicians lacked a degree of humility, which is a personal quality considered essential in allowing athlete's to dictate their own path (Friesen \& Orlick, 2010).

An interesting finding from the study was the extent to which the physicians likened their practice to that of the sport psychologist. Physicians discussed how their ability to heal relates to their personality and that 'the intervention is the person'; the personality of the sport psychologist has been similarly implicated in their ability to establish an effective therapeutic relationship and therefore the effectiveness of their work. 
The participants also alluded to the need for both physicians and psychologists to be driven by an underlying need to care for people which directs them to practice within such a profession. Dorfman (1990) suggests that of upmost importance is that an athlete must know that the sport psychologist cares about them. Gilbourne and Richardson (2006) also cite a psychologist's capacity to care as essential for successful practice, which is dictated by their "ability to embrace the self-awareness and empathic qualities that engender compassion" (p. 333). Caring has been alluded to in more recent sport psychology literature; Andersen (2009) states that "sport psychologists, their personalities and their abilities to form caring, non-contingent, positive relationships....are what fuel change" (p. 13). The consultants in Friesen and Orlicks' (2010) study considered establishing a sense of caring for a client as "a necessary component to their practice" (p. 241), and those unable to do so would find it difficult to invest in the relationship.

Medical school applicants are judged not only on their academic achievements but also their personality (Glick, 2000; Bore, Munro, \& Powis, 2009), personal qualities (Lumsden, Bore, Millar, Jack, \& Powis, 2005) and personal background (McGaghie, 1990). Perhaps, therefore, the sport psychology profession should adopt a similar approach based upon the personal qualities highlighted in this study. It may be suggested that similar to that of the counselling and medical professions, applicants to sport psychology programmes of education and training should also be judged based upon their personal qualities prior to enrolment. Moreover, there is scope within these programmes for trainee sport psychologists to consider their own personal qualities as integral to effective practice, and to place emphasis on the importance of these in self-examination of their applied work and personal development.

\section{Conclusion}

The aim of the current study was to explore the personal qualities of sport psychologists required for effective practice from the perspective of sports physicians. Several personal qualities were discussed relative to relationship building, professionalism within the applied environment, and perceived similarities between the physicians and sport psychologists. The findings both supported and extended previous counselling and sport psychology literature, and offered detail regarding how a sport psychologist's personal qualities can interact with their practice environment. Given the small number of participants recruited the findings may not be fully representative of the UK sports physician population and future research could address this by utilising a larger subject group. It would also be interesting to examine such personal qualities from the perspective of other members of a multidisciplinary support team, as doing so would enrich the personal qualities data obtained in this study. Furthermore the role of the sport psychologist, particularly in elite and professional sport environments, is becoming increasingly diverse, typified by those who now find themselves working in an organisational or human resource-like capacity (Nesti, 2010). Information regarding how a sport psychologist's personal qualities impact upon their role in managing groups would therefore be beneficial in understanding the requirements of and preparation for such roles. It would also appear important to consider what can be learnt from the counselling and medical professions in terms of the education and training of practitioners and the personal qualities that can impact upon their success. In summary, the results from this study represent detailed discussions around the qualities of effective sport psychologists, and support the growing emphasis on the importance of the person behind the practitioner.

\section{REFERENCES}

Andersen, M. (2009). Performance enhancement as a bad start and a dead end: A parenthetical comment on Mellalieu and Lane. The Sport and Exercise Scientist, 20, 12-14.

Anderson, A., Miles, A., Robinson, P., \& Mahoney, C. (2004). Evaluating the athlete's perception of the sport psychologist's effectiveness: What should we be assessing? Psychology of Sport \& Exercise, 5, 255-277.

Balague, G. (1999). Understanding identity, value, and meaning when working with elite athletes. The Sport Psychologist, 13, 89-98.

Berg, B.L. (2009). Qualitative Research Methods for the Social Sciences. ( $7^{\text {th }}$ ed.). Boston: Pearson Education. 
Bore, M., Munro, D., \& Powis, D. (2009). A comprehensive model for the selection of medical students. Medical Teacher, 31, 1066-1072.

Corey, G. (2009). Theory and Practice of Counseling and Psychotherapy. ( $8^{\text {th }}$ ed.). Belmont, CA: Thomson Brooks/Cole.

Corlett, J. (1996). Sophistry, Socrates and sport psychology. The Sport Psychologist, 10, 84-94.

Cropley, B., Miles, A., Hanton, S., \& Niven, A. (2007). Improving the delivery of applied sport psychology support through reflective practice. The Sport Psychologist, 21, 475-494.

Dorfman, H.A. (1990). Reflections on providing personal and performance enhancement consulting services in professional baseball. The Sport Psychologist, 4, 341-346.

Fifer, A., Henschen, K., Gould, D., \& Ravizza, K. (2008). What works when working with athletes. The Sport Psychologist, 22, 356-377.

Friesen, A., \& Orlick, T. (2010). A qualitative analysis of holistic sport psychology consultants' professional philosophies. The Sport Psychologist, 24, 227-244.

Gilbourne, D., \& Richardson, D. (2006). Tales from the field: Personal reflections on the provision of psychological support in professional soccer. Psychology of Sport and Exercise, 7, 325-337.

Glick, S.M. (2000). Selection for entry to medicine and specialist training. Medical Teacher, 22, 443-447.

Hack, B. (2005). Qualifications: Education and Experience. In S. Murphy (Ed.), The Sport Psych Handbook (pp. 293304). Champaign, IL: Human Kinetics.

Harter, S. (2002). Authenticity. In C.R. Snyder, \& S.J. Lopez (Eds.), Handbook of Positive Psychology (pp. 382-394). New York, NY: Oxford University Press.

Jones, C. (2007). Developing good practitioners: Issues of clarification and character. Sport \& Exercise Psychology Review, 2, 40-42.

Lindsay, P., Breckon, J.D., Thomas, O., \& Maynard, I. W. (2007). In pursuit of congruence: A personal reflection on methods and philosophy in applied practice. The Sport Psychologist, 21, 335-352.

Lumsden, M. A., Bore, M., Millar, K., Jack, R., \& Powis, D. (2005). Assessment of personal qualities in relation to admission to medical school. Medical Education, 39, 258-265.

McGaghie, W.C. (1990). Qualitative variables in medical school admission. Academic Medicine, 65, 145-149.

Nesti, M. (2004). Existential Psychology and Sport: Implications for Research and Practice. London: Routledge.

Nesti, M. (2010). Psychology in Football: Working with Elite and Professional Players. London: Routledge.

Orlick, T., \& Partington, J. (1987).The sport psychology consultant: Analysis of critical components as viewed by Canadian Olympic athletes. The Sport Psychologist, 1, 4-17.

Patton, M.Q. (2002). Qualitative Research and Evaluation Methods. ( $3^{\text {rd }}$ ed.). Sage: London.

Rogers, C. R. (1957). The necessary and sufficient conditions of therapeutic personality change. Journal of Consulting Psychology, 2, 95-103.

Shenton, A.K. (2004). Strategies for ensuring trustworthiness in qualitative research projects. Education for Information, 22, 63-75.

Stambulova, N., \& Johnson, U. (2010). Novice consultants' experiences: Lessons learned by applied sport psychology students. Psychology of Sport and Exercise, 11, 295-303.

Strupp, H.H. (1978). The therapist's theoretical orientation: An overrated variable. Psychotherapy: Theory, Research and Practice, 15, 314-317.

Taylor, J. (2008). Prepare to succeed: Private consulting in applied sport psychology. Journal of Clinical Sport Psychology, 2, 160-177.

Tod, D., \& Andersen, M. (2005). Success in Sport Psych: Effective Sport Psychologists. In S. Murphy (Ed.), The Sport Psych Handbook (pp. 303-312). Champaign, IL: Human Kinetics.

Truax, C.B., \& Carkhuff, R.R. (1976). Toward Effective Counseling and Psychotherapy: Training and Practice. New Jersey: Transaction Publishers. 
AUTHOR'S ADDRESS: Charlotte Chandler

Liverpool John Moores University

Email: c.chandler@ljmu.ac.uk 